\title{
¿Qué nos dicen los analistas en el pase?
}

\author{
Florencia Flor Farias
}

\begin{abstract}
Resumen
El artículo discute el dispositivo del pase y su transmisión en la Escuela. El dar por terminado un análisis tiene que ver con una decisión. Pero ¿quién decide? No es el analista, tampoco el analizante, es una decisión acéfala, no depende de la voluntad. Es un momento conclusivo, propio de un proceso analítico que "toma" tanto al analizante como al analista. Nos lleva a pensar el complejo tema de la autorización. En la demanda del pase a la escuela el analizante ya no se autoriza de su analista, sino que toma a su cargo la tarea de dar cuenta a Otro, que ya no es el analista, ya no anuda la pareja analizante-analista, sino analista-Escuela. El pase es una invitación al analizante para que ofrezca su experiencia de transmisión. Ya no aparece la coaptación de los superiores, sino de los iguales, los pasadores, que son también psicoanalizantes y que forman parte del proceso. El pase es la posibilidad de transmitir lo que descubrió en su análisis a otros y comprometerse con una nueva experiencia en el colectivo, la Escuela.
\end{abstract}

\section{Palabras claves:}

Autorización; Testimonios; Escuela; Pase; Deseo.

\section{What do the analysts tell us in the pass?}

\begin{abstract}
The article discusses the device of the pass and its transmission in the School. The termination of an analysis has to do with a decision. But who decides? It is not the analyst, nor the analysand, it is an acephalous decision, it does not depend on the will. It is a moment to conclude, typical of an analytical process that "takes" both the analysand and the analyst. It leads us to think about the complex issue of authorization: In the demand of the pass to the School, the analysand no longer authorizes themselves by the analyst, but rather takes on the task of accounting for the Other, no longer supports the analysand-analyst pair, but instead the analyst-School pair. The pass is an invitation to the analyst to offer their transmission experience. It no longer appears the coaptation of superiors, but of equals,
\end{abstract}


passers, who are also psychoanalysands and are part of the process. The pass is the ability to convey what you discovered in your analysis to others and commit to a new experience in the collective, the School.

\title{
Keywords:
}

Authorization; Testimonies; School; Pass; Desire.

\section{O que nos dizem os analistas no passe?}

\begin{abstract}
Resumo
$\mathrm{O}$ artigo discute o dispositivo do passe e sua transmissão na Escola. O término de uma análise tem a ver com uma decisão. Mas quem decide? Não é o analista, nem o analisando, é uma decisão acéfala, não depende da vontade. É um momento de concluir, típico de um processo analítico, que "toma” tanto o analisando quanto o analista. Leva-nos a pensar sobre a complexa questão da autorização: na demanda do passe à Escola, o analisante já não se autoriza de seu analista, mas toma para si a tarefa de dar conta do Outro, já não sustenta o par analisante-analista, mas o par analista-Escola. O passe é um convite ao analisante para oferecer sua experiência de transmissão. Já não aparece a coaptação dos superiores, mas dos iguais, os passantes, que são também psicanalisantes e fazem parte do processo. O passe é a possibilidade de transmitir o que descobriu em sua análise a outros e comprometer-se com uma nova experiência no coletivo, a Escola.
\end{abstract}

\section{Palavras-chave:}

Autorização; Testemunhos; Escola; Passe; Desejo.

\section{Qu'est ce que nous disent les analystes dans la passe?}

\section{Résumé}

Cet article a pour but de mettre en lumière le dispositif de la passe et sa transmission à l'École. Le terme d'une analyse relève d'une décision. Mais qui décide? Ce n'est ni l'analyste, ni l'analysant non plus, mais une décision acéphale (cela n'a rien à voir avec la volonté). Il s'agit d'un moment de conclure, caractéristique d'un processus analytique qui comprend à la fois l'analysant et l'analyste. Cela nous fait penser à la question complexe de l'autorisation : dans la demande de la passe à l'École, l'analysant ne s'autorise plus de son analyste, mais prend la charge de rendre compte de l'Autre, il ne supporte plus le couple analysant-analyste, mais le couple analyste-École. La passe l'invite à témoigner de son expérience de trans- 
mission. On n'y trouve plus la cooptation des supérieurs, mais celle des égaux, les passants, qui sont tout aussi des psychanalysants et font partie du processus. La passe est la possibilité de transmettre à d'autres ce qu'on a découvert dans sa propre analyse, et de s'engager dans une nouvelle expérience dans le collectif, soit dans l'École.

\section{Mots-clés :}

Autorisation ; Témoignage ; École ; Passe ; Désir.

El analista debe haber circunscripto la causa de su horror, el suyo propio, el de él, separado del de todos, horror al saber. Desde ese momento saber ser un desperdicio. Es lo que el análisis, ha debido, al menos, hacerle sentir. Si ello no le lleva al entusiasmo, bien puede haber análisis, pero analista ni por asomo. (Lacan, 1974/2012, p. 329)

¿Quién decide el final de un análisis? ¿Analizante? ¿Analista? ¿Cuándo es el momento? Mientras que en el análisis didáctico, tal como lo plantea la IPA, esto no es un problema, ya que luego de determinados años, cantidad de horas estipuladas, el trayecto se a cumplido, no ocurre lo mismo en un análisis lacaniano. Los analistas didactas forman un grupo de élite, en los que recae una gran responsabilidad institucional. Son los encargados de la formación, con el riesgo de convertirla en "adoctrinamiento". Cumplen un doble papel: terapeuta y juez. Es el analista, quien juzga que el análisis ha concluido, y muchas veces es necesario que la pareja tenga que "negociar" los acuerdos de su separación.

El riesgo es convertir al analista en candidato que sigue fielmente al maestro. Esto va a dar como resultado la tesis de la identificación al analista como final de análisis, lo que implica a la vez una identificación a la técnica y en especial al encuadre.

Lacan propone una concepción diferente del final de la cura, su tesis es: Hay un final de análisis, allí donde Freud encuentra un tope, Lacan abre una posibilidad.

El dar por terminado un análisis tiene que ver con una decisión. Pero ¿Quién decide? No es el analista, tampoco el analizante, es una decisión acéfala, sin autor, no depende de la voluntad. Es un momento conclusivo, propio de un proceso analítico que "toma" tanto al analizante como al analista. Analista que, sin embargo, tiene la responsabilidad de escuchar esa decisión. ¿Cuándo es el momento? Es frecuente que sea el analizante o el mismo analista los que jueguen sus resisten- 
cias y posterguen la partida, y se lleven a sostener el "todavía no", el "aún no es el momento", o al contrario a apresurarla.

Pero igual que en el ajedrez donde hay un jaque mate, en el análisis hay una especie de "El rey ha muerto". Un Otro que cae, analista en representación del Otro, muerte del Padre, caída de ese objeto adyecto, que ya no juega más. Tiempo lógico, tiempo en que cesan las dudas y adviene una especie de certeza, el acto analítico soportando lo incalculable.

Es frecuente que algunos testimonios digan que se les presentificaba el "Ya no tengo nada que decir", el "basta", tramos finales en que el saber ya no se espera del analista, testigo a veces silencioso de estos encuentros, en los que se preanuncia su caída.

Con el dispositivo del Pase, el analizante toma la palabra, anula el poder del didacta, denuncia la jerarquía analítica. No hay una valorización de su experiencia. Se distingue desde el comienzo de los procedimientos de habilitación tradicionales, ya que se sitúa en el campo de la auto-autorización.

Ya no es el didacta cuando decide que el candidato está en condiciones de ser analista sino será el mismo el que se autorice y desee someterse a la verificación de la Escuela.

Eso nos lleva a pensar el complejo tema de la autorización: Nos encontramos con dos principios "El analista solo se autoriza de sí mismo" y que el analizante hace el pase para hacerse autorizar como analista de la Escuela. Aunque los dos términos parezcan contradictorios, son solidarios. El primer principio (autorizar), no excluye que la Escuela garantice (Proposición) que un analista surge de su formación (Lacan, 1967/1991). Se apela a la garantía de una autentificación, por otros que comparten la misma experiencia.

El deseo del analista difícilmente puede sostenerse sin ese pasaje por los otros en la Escuela. Lacan posteriormente aclara que "el autorizarse de sí mismo" conlleva una decisión que jamás se toma aislada, sino más bien equivale a un "autorizarse de sí mismo y de algunos otros". El analista puede querer esa garantía de la Escuela para responsabilizarse de intentar dar testimonio de los problemas cruciales de la doctrina. Lo que garantiza la Escuela no es el ser del analista, sino probablemente es el lugar en que el analista podrá recuperar su acto.

En "La Nota a los italianos" (Lacan, 1974/2012, pp. 328-329) hay formulaciones fuertes, en las que recuerda su apuesta: "El analista no se autoriza más que de sí mismo". Sin embargo, es un texto tardío, en el que remarca que no quiere decir que cualquiera se autoriza como analista. El análisis es así necesario pero no suficiente para garantizar que ex-sista analista.

No hay analista a no ser que le surja el deseo de ocupar el lugar de deshecho de la docta ignorancia de la humanidad, y ahí está la condición de lo que por algún lado debe llevar la marca.

Con la introducción del Pase, se instala la cura en el corazón de la experiencia analítica, el analista mismo se propone como verificación. 
A través de su invención, el pase, logra que podamos acercarnos a las preguntas que conmueven a toda la comunidad analítica: Qué produce un análisis y qué es un analista, dos momentos que son cronológica y lógicamente diferentes en el tiempo. Es diferente el momento en que el sujeto finaliza su análisis de aquel en el que decide tomar a su cargo la tarea de dar cuenta de lo mismo a otros que ya no es su analista. Por otro lado, en la demanda del Pase a la Escuela el analizante ya no se autoriza de su analista, sino que toma a su cargo la tarea de dar cuenta a Otro, que ya no es el analista, ya no anuda la pareja analizante-analista, sino analista-Escuela.

¿Qué se verifica en el Pase? ¿Que evalúa el jurado? Una pregunta que no tiene una sola respuesta y que hay diversidad en los diferentes jurados del Cartel.

Aunque en la práctica los pasantes testimonian sobre la trayectoria de su análisis y del saldo obtenido al final, y los carteles evalúan si un sujeto arribó al final, Lacan dejó la posibilidad de que esté abierto a aquellos que aún no han terminado su análisis.

En "El Atolondradicho" (Lacan, 1974/1984) plantea la distinción entre el viraje y el final de análisis, distinción que no queda tan clara en otros textos, por ejemplo en la Proposición nos dice que el psicoanálisis se constituye "como experiencia original" si llega hasta el punto que "permite figurar su finitud" (Lacan, 1967/1991, p. 10), finitud que no es necesariamente el fin de análisis, pueden no coincidir, sino el momento en que el analizante puede encontrar un punto de detención, de basta, en el que se detenga la cadena de significantes a descifrar, para ello necesitamos de la presencia del objeto "a", para obtener ese punto de finitud (Soler, 1988, inédito).

Si bien no existen criterios para realizar las nominaciones, algunos Carteles esperan que al término del análisis haya podido surgir un deseo nuevo. El sujeto experimenta como una ganancia de deseo. Deseo que no se sustenta más del Otro. El pase al Deseo del analista es el pase de Lacan. Saber como un analizante se hace analista. Pedir el Pase es poner en cuestión con fines de examen su propia destitución subjetiva. Será categórico: lo único que produce a un analista es su análisis, al final se está en condición de ejercer la función.

Es el intento de verificar el viraje de analizante a analista, para intentar responder a la pregunta: "Qué es un analista".

Entonces, si el pase nos permite decir que hay analista es porque sin embargo no podemos decir aún, sabiendo que hay, qué es: Este es el prime saber que el pase nos enseña. En tanto hay nominación, este saber no es universable en el sentido de determinar un ser. Nadie dice qué es un analista. La nominación no responde a la pregunta por el ser del analista, no dice lo que es, sino a la pregunta si lo hay o no. La apuesta sigue abierta, al uno por uno.

La persona que pide el Pase no lo hace en tanto psicoanalista, sino en tanto psicoanalizante. El Pase no garantiza ninguna práctica, ningún hacer del analista. 
La Escuela no es garante absoluto, no hay otro modo de volverse analista, es decir, no hay una solución estándar de la producción del deseo del analista. La cuestión ya no es quien tiene derecho a titular analistas, sino es poner a trabajar en la Escuela la pregunta ¿Qué es un analista? Sabiendo que siempre va a quedar un punto de no saber, un punto de incógnita.

\section{La enseñanza de los AE}

Entonces, ¿Qué enseñan los testimonios de los AE?, ¿Cómo un testimonio del Pase deviene enseñanza?, ¿Cómo pasar de la singularidad de la experiencia a una enseñanza posible "para todos" o quizás para algunos?

El Pase es una invitación al analizante para que ofrezca su experiencia de transmisión. Ya no aparece la coaptación de los superiores, sino de los iguales, los pasadores, que son también psicoanalizantes y que forman parte del proceso.

Es la posibilidad de transmitir lo que descubrió en su análisis a otros y comprometerse con una nueva experiencia dentro de lo colectivo, la Escuela.

Los testimonios de los AE son solo una parte de la transmisión en la Escuela, es decir están los carteles, su enseñanza, los efectos de la nominación en la comunidad.

Sin el pase nada garantiza que el fin de análisis sea una creencia más. Se puede demostrar que la experiencia analítica no es del orden de lo inefable, y que el pasaje de analizante a analista no involucra una experiencia mística.

Llevar el análisis hasta el final implica volverse psicoanalista de su propia experiencia. Es tener otra distancia frente a su propio análisis, permite ver su propia neurosis con relación al psicoanálisis, a la teoría y a sus problemas. Aquello que le enseñó ese análisis, ya no lo guarda para sí, sino que lo transmite a los otros, gracias al Pase.

En los testimonios se sitúa un núcleo de verdad particular, del cual surge la elaboración de saber que se vuelve transmisible, posibilitando esa inédita articulación entre lo más singular del sujeto y lo generalizable de un saber expuesto.

El testimonio es particular, pero vale para todos. Pero para cada uno vale singularmente en el recorrido de la pulsión. Los testimonios señalan una diversidad con la que justamente se puede hacer serie. Los testimonios muestran la posibilidad de hacer serie con la diferencia, éste es un punto señalado muy claramente en la propuesta de Lacan sobre el Pase.

El propio nombramiento de un Analista de Escuela, al exponer su particularidad clínica, hace agujero en el conjunto de un saber todo.

En este dispositivo no es solo el testimonio del AE el que se transmite. Están implicados no solo el pasante, también los pasadores, los carteles, el éxtimo cuando lo hay, y toda la comunidad analítica. 


\section{La relación al saber}

Es posible hacer de la transmisión de la experiencia del pase, enseñanza. El saldo del Pase debe ser su contribución al saber.

Pero alojar el saber en el lugar de la verdad es condición necesaria pero no suficiente, puede que ese saber deje al analista como un simple sujeto de un semblante de mera elocuencia y disertación.

En muchos de los testimonios hay bastante dedicado en relación al saber, se remarca cómo se vuelve decisivo para la producción de un analista el cambio de posición del sujeto con respecto al saber. Lo que caracteriza esa ganancia de saber hacer con aquello que se ha sido como objeto en el deseo del Otro, las condiciones de goce que el significante recubre, y un saber hacer sobre eso.

Ese empuje al saber que el dispositivo del Pase propone, lleva a una elaboración sobre esa ganancia de saber más conclusiva. Algunos testimonios caen en ciertos clisés teóricos, reiterando doctrinas y no se diferencian de exposiciones teóricas, pero otros, además de estar acompañados de una parte de doctrina, se pueden atisbar como un núcleo de verdad singular, en donde surge un saber transmisible.

Apunta antes que nada a alojar los restos del propio análisis, para que lo indecible permita que algo sea dicho.

\section{La relación con el Otro}

La demostración de saber en el Pase implica, entonces, que se trata de demostrar hasta que punto una elaboración de saber ha sido llevada hasta poner en evidencia la inconsistencia del Otro, permitiendo sacar a luz qué es lo que el sujeto había inventado como truco, como artificio, ya sea en el orden del fantasma, del síntoma, para suplir la falla radical de la estructura, para hacer existir al Otro y por lo tanto a la relación sexual.

En todos los testimonios son innegables los logros terapéuticos. Hay sobre todo cambios a nivel del amor, del sufrimiento, del separarse de la angustia, del soportar la falta, de tener mayor libertad en cuanto a la elección del partenaire.

Elaboración de la falta, como falta de saber sobre el sexo. Se adquiere un saber de lo imposible y también saber de la singularidad, saber sobre su manera propia de arreglárselas con su falta y de compensarla.

Lacan advirtió que la lógica del fin de análisis implica darle un nuevo destino a las marcas del sujeto.

Hay una nueva disposición de la libido, que se invierte en el trabajo, en el amor o en un nuevo realce a las sublimaciones del sujeto.

Al final cambia el estatuto del Otro: lo hace desvanecer, y el sujeto desprendido del Otro atempera, por un tiempo su disputa, su reivindicación. 


\section{Atravesamiento del fantasma e identificación al síntoma}

Según la época de su enseñanza Lacan pondrá el énfasis en que al final el fantasma se reduce a la pulsión, o bien que al final el sujeto se identifica con su síntoma, con aquello del síntoma que se muestra más real, imposible de transformar. El sujeto se encontrará seguramente aliviado de sus síntomas, ya que se producen efectos terapéuticos, los síntomas se reducen, se transforman, hay alivio del padecer, el sujeto deja de dar consistencia al Otro, esto es, se enfrenta con la castración, y logra cambiar su posición respecto de ella.

También podemos pensar qué ocurrió con el fantasma, es decir con la condición de goce. Hay atravesamiento del fantasma cuando el sujeto ya no cree en su ficción, esto produce efectos tanto en la relación al Otro, como en el ser.

Todos testimonian a su manera, que el psicoanálisis les ha avisado de la falta en ser, pero no siempre de la manera en que se esperaba.

Para unos, es por la travesía del fantasma: hay como un efecto de libertad, es decir de la posibilidad, que da acceso a la contingencia, flexibilización de las condiciones de amor que domina a las elecciones de objeto. Luego de las caídas de las identificaciones fundamentales del Edipo, se consigue avanzar un poco más en relación a lo real que cubría el fantasma, es decir el goce pulsional que cae de él.

Otros testimonian sobre la Identificación al síntoma, se han transformado en el síntoma ellos mismos: son su síntoma, y el fin del análisis es la revelación del goce de ese síntoma, lo que pone fin a la falta de ser. "Saber hacer con su síntoma”, es decir que hay un consentimiento con su modo de gozar a través del síntoma. Sabe cuál es ese resto de goce que lo divide y se reconoce en él. Ese goce que creía que estaba en el Otro se le vuelve como lo más propio del sujeto, así logra su efecto de ser. Lo incurable es aquel cuyo síntoma compensa "bastante" la ausencia de relación sexual, es un síntoma endurecido, aceptable, y para el neurótico esto es un cambio.

La tesis de Lacan es que se trata de recuperar algo del ser, en forma de conquistar un "yo soy" que ya no pase por el Otro, es decir, que habiendo hecho un trabajo con el inconsciente, lo enfrente a un "Tú eres eso", que metaforiza lo que soy. Es un ser que incluye la castración, el sujeto de algún modo se acepta.

Cuando el sujeto asume su propia determinación podrá aparecer un margen de libertad, cierta liberación de esa causa que el sujeto fue para el deseo del Otro.

Se vuelve el sujeto capaz de elegir, menos inhibido, menos impedido, en suma más decidido y combativo.

\section{Destitución subjetiva - deseo del analista}

Lacan utiliza el término de "destitución subjetiva" para describir el final, en la cual el sujeto ve abolirse, realizándose como deseo. El sujeto destituido ya no espera del Otro, más allá de los logros terapéuticos, es importante lo que el sujeto hace con el saber adquirido. Qué hace el sujeto con sus marcas, el momento en que el sujeto 
se percata, que se disuelve la consistencia del Otro, no dice aún nada acerca de cuál será el nuevo lazo con el Otro inconsistente que el sujeto va a sostener.

El analista debe ir más allá, animarse a atravesar la puerta del saber, para dar cabida a un deseo nuevo, inédito. El deseo del analista es por definición un deseo donde el Otro falta.

Aparece el fin del análisis como la posibilidad de convertir el tiempo de concluir en una obra. Hay una satisfacción en juego, pero no mortífera. Cada sujeto tiene que encontrar que es para él esa obra que le permitirá metaforizar, lo que es. Llegar a lo que Lacan propone como final de análisis al: “Tú eres eso", que es otra manera de decir: "Saber hacer con su síntoma" y que apunta a lo que queda de resto, de incurable, ligado al goce. Por lo tanto, no podemos sostener un sujeto sin síntoma, sino un sujeto amigado con su síntoma.

Tema también para detenernos a pensar cual sería la diferencia entre fin de análisis vía obra, vía sublimación. Sabemos que el fin del análisis no es la represión, y su contrario es la sublimación. Sin embargo, el analizado tampoco se convierte en un artista, sino en analista.

Obra es un efecto del análisis, diferente del artista en la que su obra es también efecto del inconsciente. Arte se construye con "la estofa de la fantasía".

La función del deseo del analista es hacerse causa del deseo. El deseo del analista en la medida en que es un deseo de "la diferencia absoluta", es un deseo de revelación de lo que es el sujeto. Pero el final no nos deja en la impotencia, abatido en el sin sentido de la vida. El haberse desprendido del Otro, no implica que el encuentro con el Otro no es posible, al contrario no es un fin solitario, autista, regodeándose en su deseo.

Lacan enuncia diferentes formas de vivir la pulsión, una de ella se refiere al saldo cínico, no poder ligar el resto pulsional a la causa del deseo, a un nuevo lazo al Otro, al Otro que no existe. Un riesgo es que se fabrique un "no incauto", creer que está de vuelta de las otras causas, desilusionado, por lo tanto las trata irrespetuosamente, se embandera de la posición de analista con mayúscula, de verdadero analista, "disfrazarse de psicoanalista", se llega a hacer una farsa para los otros que se la creen.

En varios textos Lacan remarca que un fin de análisis auténtico deja muchas posibilidades al sujeto. La vida comienza a tener otra significación, el sujeto querrá vivirla porque encuentra un plus de gozar en vivir, las miserias cotidianas adquieren otro valor, el asumir la castración la muerte hace que cambie el punto de vista de lo que vale la pena.

Final que es un comienzo también. Hay saldo en relación al humor, una relación que permite sobrellevar las desgracias que le tocan al sujeto. Tener una actitud distinta ante la historia de su neurosis. Que nuestra historia, dice Lacan, termine siendo una historia aligerada de sufrimiento, reescribirla como buena historia, y una buena historia tiene siempre un toque de humor. Si Freud nos dice que todo ser humano tiene el deber de "soportar la vida", habría que agregarle... con humor. Es la liberación de sentido, de ese lastre que encadena al sujeto al mito tragicómico de su neurosis, el que permitirá el encuentro con el sin sentido de 
los significantes que estructuraron su vida, este vaciamiento del sentido termina acarreando un efecto de humor que no debe confundirse con la comicidad.

Algo se aprende sobre sí mismo en el análisis, sobre lo que se es, pero eso deja lugar a lo que no se sabe, aún un análisis llevado a su término, deja una parte de no sabido.

El deseo no es un deseo triste, es un deseo que conmociona, y que puede llevar al entusiasmo.

\section{Referencias bibliográficas}

Colección Orientación Lacaniana. Enseñanzas del pase. Buenos Aires: EOL.

Farías, F. (2004). El síntoma al final del análisis. Presentado en Memorias de las XII Jornadas de Investigación en la Facultad de Psicología de la Universidad de Buenos Aires, Buenos Aires, Argentina.

Freud, S. (1913/1993). Sobre la iniciación del tratamiento. In S. Freud. Obras completas (Vol. XII). Buenos Aires: Amorrortu.

Freud, S. (1937/1993). Análisis terminable e interminable. In S. Freud. Obras completas (Vol. XXIII). Buenos Aires: Amorrortu.

Lacan, J. (1967/1991). Proposición del 9 de octubre de 1967 sobre el psicoanalista de la Escuela. In J. Lacan. Momentos cruciales de la experiencia analítica (pp. 7-23). Buenos Aires: Manantial.

Lacan, J. (1967/2012). Discurso en la Escuela Freudiana de París. In J. Lacan. Otros escritos (pp. 279-299). Buenos Aires: Paidós.

Lacan, J. (1973/2012). Introducción a la edición alemana de un primer volumen de los Escritos. In J. Lacan. Otros escritos (pp. 579-585). Buenos Aires: Paidós.

Lacan, J. (1974/2012). Nota italiana. In J. Lacan. Otros escritos (pp. 327-332). Buenos Aires: Paidós.

Lacan, J. (1975/2006). El seminario 23: el sinthome. Buenos Aires: Paidós.

Lacan, J. (1977). Psicoanálisis, radiofonía y televisión. Barcelona: Anagrama.

Lacan, J. et al. (1975/1984). El atolondrado, el atolondradicho o las vueltas dichas.

In J. Lacan. Escansión (pp. 15-69). Buenos Aires: Paidós.

Soler, C. (1988). Finales de análisis. Buenos Aires: Manantial.

Soler, C. (2002). La destitución subjetiva. Seminário apresentado no Foro Psicoanalítico de Buenos Aires, Argentina. Inédito.

Recebido: 17/04/2018

Aprovado: 26/06/2018 